\title{
Resinas Sulfônicas: Síntese, Caracterização e Avaliação em Reações de Alquilação
}

Fernanda M. B. Coutinho
Departamento de Processos Químicos, IQ, UERJ e IMA, UFRJ

Maria Luz Aponte

Instituto de Macromoléculas Professora Eloísa Mano, UFRJ

Celina C. R. Barbosa

Instituto de Engenharia Nuclear, CNEN

Valéria G. Costa, Elizabeth R. Lachter, David Tabak Departamento de Química Orgânica, IQ, UFRJ

\begin{abstract}
Resumo: Três resinas catiônicas (Amberlyst 15, Lewatit SPC 112, ambas comerciais e MLS 07, sintetizada em laboratório) foram utilizadas como catalisadores em reação de alquilação. A resina MLS 07, obtida pela copolimerização em suspensão do estireno com divinilbenzeno, foi sintetizada de modo que apresentasse tamanho médio de partícula e porosidade próximos aos da resina Amberlyst 15. MLS 07 foi modificada por meio de reação de sulfonação dos anéis aromáticos, que introduziu no material, grupos ativos $\left(\mathrm{SO}_{3} \mathrm{H}\right)$. As três resinas, selecionadas em duas faixas granulométricas, foram caracterizadas por adsorção de nitrogênio (área específica, volume de poros e diâmetro médio de poro), por microscopia eletrônica de varredura (morfologia) e quanto a sua capacidade de troca iônica. Os catalisadores foram utilizados em reações de alquilação de tolueno com álcool benzílico. Foi observada a influência de parâmetros como: tamanho médio de partícula, morfologia, tipo de catalisador e temperatura na conversão do álcool benzílico e na seletividade da formação do produto de interesse, benziltoluenos (orto, meta e para). As resinas Amberlyst 15 e MLS 07 apresentaram melhores resultados quando comparadas com a Lewatit SPC 112 que apresentou menor atividade e seletividade no produto de interesse em todas as condições de reação utilizadas. Esse resultado pode ser atribuído principalmente à menor área específica desse material em relação às outras duas resinas.
\end{abstract}

Palavras-chave: Resinas sulfônicas, síntese, caracterização, catálise heterogênea, alquilação, álcool benzílico, benziltolueno.

\section{Ion-Exchanges Resins: Synthesis, Characterization and Evaluation in Alkylation Reaction}

Abstract: Three cationic resins (commercial Amberlyst 15 and Lewatit SPC112, and MLS 07, synthesized in our laboratory) were utilized as catalysts in alkylation reactions. MLS07 resin, prepared by suspension copolymerization of styrene and divinylbenzene, was produced in selected conditions in order to present average particle size and porosity close to those of Amberlyst 15. The $\mathrm{SO}_{3} \mathrm{H}$ active groups were introduced in the MLS07 resin by sulfonation of the aromatic rings. Samples of the three resins, of two granulometric ranges each, were charactherized by nitrogen adsorption (specific surface area, pore volume and average pore diameter), electron scanning microscopy (morphology) and by their ion exchange capacity. The catalysts were used in alkylation reactions of toluene with benzyl alcohol. The influence of parameters such as avarage particle size, morphology, catalyst type and reaction temperature on the conversion of the benzyl alcohol and on the reaction selectivity relative to the formation of benzyl-toluene, was studied. The data obtained show that Amberlyst 15 and MLS 07 presented better performance as compared to that of Lewatit SPC112. In all the reaction conditions employed Lewatit SPC 112 showed the lowest activity and selectivity in the formation of the desired product $(o-, m-, p$ - benzyltoluene $)$. This behavior may be mainly attributed to the fact that Lewatit SPC112 has the lowest surface area of the three resins.

Keywords: Ion-exchange resins, synthesis, characterization, heterogeneous catalysis, alkylation, benzyl alcohol, benzyltoluenes.

Autor para correspondência: Fernanda M. B. Coutinho, Instituto de Química, UERJ e IMA/UERJ, Caixa Postal 68525, CEP: 21945-970, Rio de Janeiro, RJ E-mail: fern@ima.ufr..br 


\section{Introdução}

Um dos maiores desafios da indústria química nos últimos anos é o desenvolvimento de tecnologias alternativas que sejam mais limpas, seguras e menos agressivas ao ambiente. Os processos devem ser eficientes em termos de consumo de energia e matéria-prima, e produzir o mínimo de rejeitos. Tem-se verificado que a grande quantidade de subprodutos, produzidos sob a forma de sais inorgânicos, por kg de produto, aumenta substancialmente quando se comparam diferentes setores da indústria química (química fina e fármacos). O aumento do fator $\mathrm{E}$, definido por Sheldon ${ }^{[1]}$ como $\mathrm{kg}$ de subprodutos/kg de produto, se deve parcialmente às sínteses em etapas múltiplas.

O ponto-chave para minimizar a quantidade de rejeitos é a melhoria dos processos no que diz respeito à seletividade e, conseqüentemente, à substituição de rotas clássicas por rotas catalíticas. Um processo catalítico heterogêneo em fase líquida apresenta inúmeras vantagens como, alta atividade e seletividade, possibilidade de reutilização do catalisador, facilidade de separação do produto, diminuição de problemas de corrosão e ambientais. Muitos esforços têm sido feitos para se desenvolver catalisadores sólidos que possam ser reutilizados e que sejam menos agressivos ao ambiente como as zeólitas, argilas ácidas entre outros para a reação de FriedelCrafts $^{[1,2]}$, muito empregada na indústria química.

$\mathrm{Na}$ indústria petroquímica essas alquilações são usualmente catalisadas por $\mathrm{AlCl}_{3}, \mathrm{HF}$ ou alumina impregnada com ácido fosfórico, embora a sua seletividade seja baixa e a corrosão alta ${ }^{[2,3]}$. Assim, o desenvolvimento de técnicas catalíticas alternativas traria um grande impacto para a melhoria dos processos em termos econômicos e ambientais.

O uso de resinas trocadoras de íons ${ }^{[4]}$, heteropoliácidos ${ }^{[5]}$, zeólitas $^{[6,7]}$ e $\operatorname{argilas}^{[8]}$ como substitutos de ácidos líquidos, tem crescido muito nos processos de alquilação de aromáticos, acilação, isomerização, hidratação e desidrociclização.

Entre os catalisadores poliméricos mais utilizados estão as resinas de estireno-divinilbenzeno com grupos sulfônicos. Essas resinas são normalmente preparadas em duas etapas. A primeira etapa consiste na síntese do copolímero de estireno/divinilbenzeno por meio de polimerização em suspensão. A estrutura porosa dos copolímeros é produzida com adição de diluentes inertes à mistura monomérica, que ao serem removidos, após o término da polimerização, liberam os poros. As características morfológicas dessas resinas (volume total de poros, distribuição de tamanhos de poro e área específica) dependem do tipo e quantidade dos diluentes, bem como do grau de ligações cruzadas. Conseqüentemente, a morfologia desses materiais pode variar desde estruturas tipo gel até macroporosas. A funcionalização é produzida em uma segunda etapa, por sulfonação do copolímero. A atividade do catalisador polimérico é influenciada pelas características da resina e pelo teor de grupos sulfônicos incorporados. As resinas trocadoras de cátions, principalmente as macroporosas, são catalisadores versáteis e podem ser utilizadas em substituição ao seu análogo homogêneo em diver- sas reações orgânicas. Geralmente a pureza do produto e o rendimento são maiores com essas resinas, que podem ser utilizadas, tanto em meio aquoso como em meio orgânico ${ }^{[4]}$. Recentemente foram feitas revisões exaustivas sobre a utilização de resinas trocadoras de íons em processos industriais, como a síntese de éteres (éter metil-trec-butílico-MTBE) e processos de laboratório $^{[4,9,10]}$. Esse tipo de catalisador é efetivo em reações de alquilação de fenóis com olefinas ${ }^{[4]}$. Entretanto, a baixa reatividade/estabilidade das resinas ácidas dificulta sua utilização na alquilação de benzeno. São relatados na literatura ${ }^{[4,9]}$ alguns estudos fundamentais sobre reações de alquilação de hidrocarbonetos aromáticos com olefinas, em meio apolar e na presença desses catalisadores. Contudo, há poucos estudos sobre a atividade catalítica das resinas trocadoras de cátions, na alquilação de hidrocarbonetos aromáticos com álcoois. Olah e colaboradores verificaram que, na alquilação de hidrocarbonetos aromáticos com metanol em presença da resina sulfônica fluorada, NAFION-H, o grau de conversão do metanol dependia da nucleofilicidade do hidrocarboneto aromático ${ }^{[11]}$. Em trabalhos posteriores, Olah verificou que a reação de alquilação de benzeno e tolueno com álcool benzílico em presença da resina sulfônica fluorada, NAFION-H, fornecia o produto de benzilação de interesse com alta seletividade ${ }^{[12]}$. Lachter e colaboradores verificaram que a alquilação do benzeno, tolueno e anisol com álcool benzílico catalisada pela resina Amberlyst 15, resina menos ácida do que a NAFION-H, forma o produto de benzilação de interesse com alta seletividade e alto rendimento ${ }^{[13]}$. Não foi realizado até o momento nenhum estudo sistemático sobre a atividade catalítica de resinas sulfônicas macroporosas, à base de estireno-divinil-benzeno, como catalisadores em reações de alquilação.

Assim, este trabalho teve como objetivo a síntese, a caracterização e a avaliação de resinas sulfônicas, como catalisadores, em reações de alquilação de tolueno com álcool benzílico. Este estudo visa o desenvolvimento de catalisadores poliméricos em processos de interesse da indústria química e que não gerem efluentes nocivos ao meio ambiente.

\section{Experimental}

\section{Materiais}

Os principais reagentes utilizados neste trabalho foram usados como recebidos. A resina Amberlyst 15 foi doada pela Rohm \& Haas e a resina Lewatit SPC 112 foi doada pela Bayer.

\section{Métodos}

Polimerização da resina MLS 07: Em balão de três bocas, equipado com agitador mecânico, condensador de refluxo e borbulhador de nitrogênio, contendo a fase aquosa [gelatina $0,06 \%(\mathrm{p} / \mathrm{v})$, hidroxietilcelulose $0,15 \%(\mathrm{p} / \mathrm{v})$ e cloreto de sódio $0,6 \%(\mathrm{p} / \mathrm{v})$, em relação ao volume de água] foi adicionada, sob agitação mecânica de $400 \mathrm{rpm}$, a fase orgânica constituída pelos monômeros estireno (Sty, cedido pela Nitriflex) e divinilbenzeno (DVB, cedido pela Nitriflex), 
pelo iniciador AIBN, cedido por cortesia da Metacril, (1\% em relação ao número total de moles dos monômeros) e pela mistura diluente tolueno/heptano [30:70 (v/v)] com um grau de diluição de $100 \%$. A relação volumétrica entre a fase aquosa e a fase orgânica foi de 4:1. A mistura reacional, sob agitação $(400 \mathrm{rpm})$, foi mantida a $70{ }^{\circ} \mathrm{C}$, em banho termostatizado, por $24 \mathrm{~h}$.

Sulfonação: O copolímero Sty-DVB, previamente inchado com 1,2-dicloroetano (10 mL de solvente/g de resina), foi sulfonado em ácido sulfúrico concentrado $(15 \mathrm{~mL}$ de ácido/g de resina, ) a $70{ }^{\circ} \mathrm{C}$ em banho-maria por $1 \mathrm{~h}$.

As resinas foram peneiradas, antes de sua purificação, em peneirador mecânico, sob leito úmido, por $30 \mathrm{~min}$.

Purificação e condicionamento das resinas comerciais e sintetizada: A purificação das resinas se faz necessária para que sejam eliminados resíduos de monômeros que possam estar presentes no material. Sendo assim, as pérolas foram lavadas com acetona, água destilada, metanol e posteriormente colocadas em estufa à $50 \pm 2{ }^{\circ} \mathrm{C}$ para secagem, por aproximadamente $1 \mathrm{~h}$. O condicionamento foi feito percolando-se metanol seco em volume pelo menos três vezes superior ao volume da resina, em uma vazão aproximada de $3 \mathrm{~mL} / \mathrm{min}$. Ao final da percolação, a coluna foi colocada em estufa à vácuo à $100 \pm 1{ }^{\circ} \mathrm{C}$ por $2 \mathrm{~h}$. Em seguida, as resinas foram transferidas, ainda quentes, para frascos secos e colocadas em dessecador.

Caracterização das resinas: A resina MLS 07 e as duas resinas comerciais (Amberlyst 15 e Lewatit SPC 112) foram caracterizadas quanto a sua capacidade de troca iônica, área específica, volume de poros, diâmetro médio de poro e morfologia.

Análise da área específica (método BET), volume de poros (método BJH) e diâmetro médio de poros: As análises foram realizadas em aparelho ASAP 2010.

Análise por microscopia eletrônica: A análise morfológica foi realizada em amostras recobertas por fina camada de ouro em microscópio eletrônico de varredura (Zeiss Germany DMS 940 A), utilizando uma voltagem de $20 \mathrm{kV}$ e uma distância de trabalho de $12 \mathrm{~mm}$ com aumentos de 5000 e 30000 vezes.

Capacidade de troca catiônica das resinas sulfônicas: Uma solução $0,25 \mathrm{M}$ de sulfato de sódio foi preparada e vertida em uma coluna contendo 0,5 g de resina seca. Após percolação desta solução o efluente proveniente da coluna foi recolhido em erlenmeyer de $500 \mathrm{~mL}$ e titulado com solução de hidróxido de sódio $0,1 \mathrm{~N}$, utilizando-se fenolftaleína como indicador. A capacidade de troca é dada como miliequivalentes de grupos sulfônicos por grama de resina seca (meq/g).

Reação de Alquilação: Em balão de fundo redondo de duas bocas com $25 \mathrm{~mL}$ de capacidade, ao qual foi adaptado um condensador de refluxo, foram adicionados, nesta ordem, álcool benzílico, tolueno e a resina na proporção molar de 200:10:0,5 (meq/g $\mathrm{SO}_{3} \mathrm{H}$ ), respectivamente. Alíquotas de $100 \mu \mathrm{L}$ da mistura foram periodicamente retiradas do meio reacional e analisadas por cromatografia gasosa de alta reso- lução. As reações foram realizadas em três diferentes temperaturas: 60,80 e $100{ }^{\circ} \mathrm{C}$, sob agitação magnética por $3 \mathrm{~h}$.

Análise Cromatográfica: As alíquotas da mistura reacional foram analisadas, para o acompanhamento da formação dos produtos, por meio de cromatografia gasosa em aparelho Varian 3800 com o injetor a $250{ }^{\circ} \mathrm{C}$ e o detector a $280^{\circ} \mathrm{C}$. A programação de temperatura foi de 80 a $220{ }^{\circ} \mathrm{C}$, $10{ }^{\circ} \mathrm{C} / \mathrm{min}$ e 220 a $280{ }^{\circ} \mathrm{C}, 30{ }^{\circ} \mathrm{C} / \mathrm{min}$ utilizando como gás carreador o hidrogênio a uma vazão de $2 \mathrm{~mL} / \mathrm{min}$. A técnica de injeção usada foi o split 1:20, com um volume de injeção de $1,0 \mu \mathrm{L}$.

\section{Resultados e Discussão}

Na Tabela 1 são apresentados os resultados de área específica, volume de poros, diâmetro médio de poros e capacidade de troca iônica das resinas utilizadas.

Pode se observar que as resinas Amberlyst 15 e a resina MLS 07 apresentam valores de área específica, volume de poros, diâmetro médio de poros e capacidade de troca, próximos. A resina Lewatit apresentou menor área específica e menor capacidade de troca iônica das resinas utilizadas.

\section{Análise por microscopia eletrônica de varredura (MEV)}

As Figuras 1, 2 e 3 apresentam as micrografias de microscopia eletrônica de varredura do interior das pérolas das resinas Amberlyst 15, Lewatit SPC 112, e MLS 07, respectivamente. As resinas MLS 07 e Amberlyst-15 não apresentaram grande diferença em termos de morfologia. A resina MLS-07 é constituida de microesferas maiores, que geram poros de maior volume, porém em número menor do que na resina Amberlyst 15, que por sua vez apresenta poros de menor volume e em maior número. Essas combinações de número de poros e volume individual de poros acabam resultando em volumes totais de poros próximos para estas duas resinas. Pode-se observar nitidamente que a resina Lewatit SP 112 apresenta uma estrutura mais compacta, menos porosa.

\section{Reação de Alquilação}

A alquilação de compostos aromáticos é uma reação de substituição eletrofílica e como tal é influenciada pela presença de substituintes, doadores ou captores de elétrons, no

Tabela 1. Propriedades das resinas Amberlyst 15 e Lewatit SPC 112 (comerciais) e da resina MLS 07 (sintetizada).

\begin{tabular}{lccc}
\hline Propriedades & Amberlyst 15 & Lewatit SPC 112 & MLS07 \\
\hline $\begin{array}{l}\text { Área específica } \\
\left(\mathrm{m}^{2} / \mathrm{g}\right)\end{array}$ & 53,4 & 26,6 & 49,1 \\
$\begin{array}{l}\text { Volume de poros } \\
\left(\mathrm{cm}^{3} / \mathrm{g}\right)\end{array}$ & 0,37 & 0,15 & 0,35 \\
$\begin{array}{l}\text { Diâmetro médio } \\
\text { de poros }(\AA)\end{array}$ & 282 & 223 & 281 \\
$\begin{array}{l}\text { Capacidade de } \\
\left.\text { troca (meq } \mathrm{SO}_{3} \mathrm{H} / \mathrm{g}\right)\end{array}$ & 3,8 & 2,6 & 4,0 \\
\hline
\end{tabular}




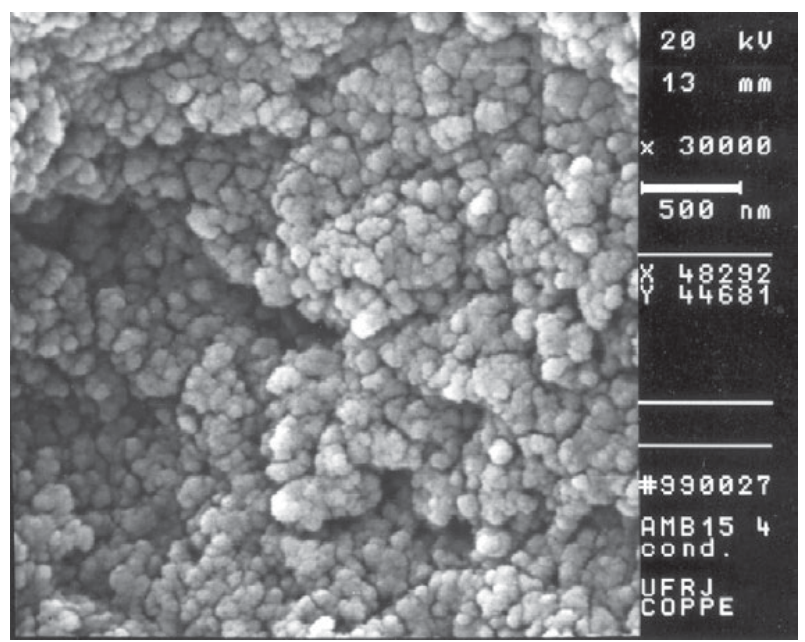

Figura 1. Microscopia do interior da resina Amberlyst 15.

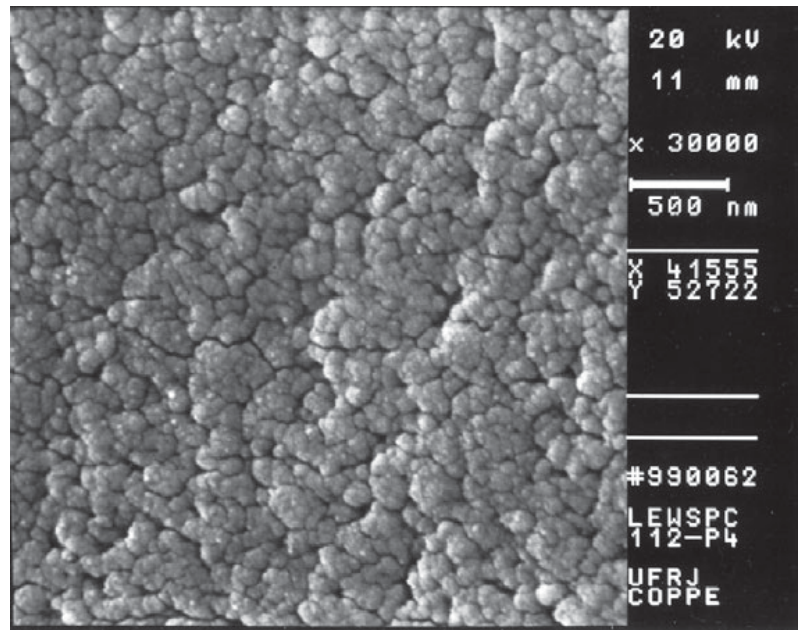

Figura 2. Microscopia do interior da resina Lewatit SPC 112.

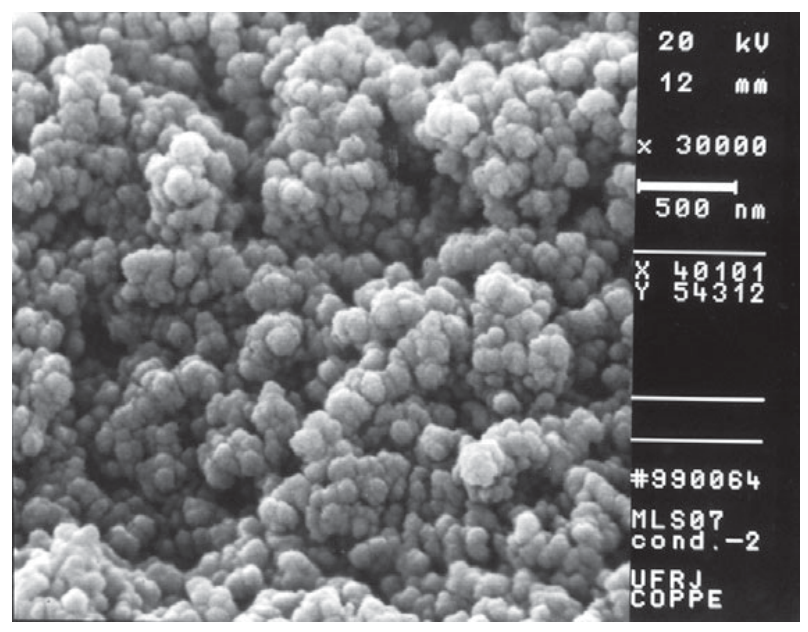

Figura 3. Microscopia do interior da resina MLS 07.

substrato aromático. Neste caso, o tolueno, que contém um grupamento doador de elétrons $\left(\mathrm{CH}_{3}\right)$, as posições do anel mais ativas são as orto e a para.

A representação esquemática das reações do tolueno com álcool benzílico em presença de resinas comerciais

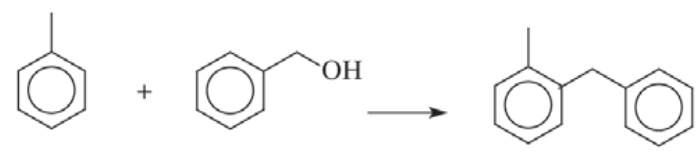

(1)

(2)

(3)

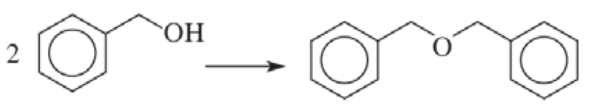

(2)

(4)

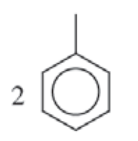

(1)

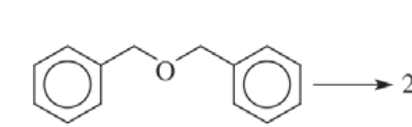

(4)

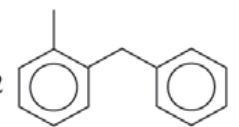

(3)
Figura 4. Esquema da reação do tolueno com álcool benzílico 1 = tolueno; 2 = álcool benzílico; 3 = benziltolueno; 4 = éter benzílico.

(Amberlyst 15, Lewatit SPC 112) e da resina MLS 07 é mostrada na Figura 4. Nessa reação, foi observada a influência de parâmetros como tamanho de partícula, temperatura e tipo de catalisador na conversão do álcool e na seletividade em relação à formação do produto de interesse, benziltolueno. Entretanto, em presença de catalisador do tipo de ácido de Bronsted pode ocorrer a autoeterificação do álcool benzílico, formando o éter benzílico como sub-produto.

\section{Efeito do tamanho de partícula}

Resinas, com tamanhos de partícula de 0,4 e 0,6 mm, foram usadas para se verificar o efeito desse parâmetro na conversão e na seletividade dos produtos formados. Esses tamanhos foram escolhidos, por terem sido obtidos em maior quantidade após o peneiramento. Os resultados estão apresentados na Tabela 2.

Verificou-se que em todas as reações conduzidas a $80^{\circ} \mathrm{C}$, a conversão do álcool diminuiu com o aumento do tamanho de partícula de 0,4 para 0,6 mm, como seria de se esperar. Partículas menores, para uma mesma massa de catalisador, oferecerão um maior número de sítios catalíticos e assim uma maior conversão. Essa diminuição da conversão, com o aumento do tamanho de partícula, foi mais acentuada para a resina MLS 07 e praticamente não variou no caso da Lewatit SPC 112. Não se verificou variação significativa na seletividade dos produtos com o aumento do tamanho de partícula. As resinas com menor tamanho de partícula foram então utilizadas para estudar o efeito da temperatura de reação e da morfologia da resina sulfônica na reação de alquilação.

\section{Efeito da temperatura}

As reações conduzidas a $60{ }^{\circ} \mathrm{C}$ levaram a uma baixa conversão do álcool, para as três resinas estudadas (Figuras 5,6 e 7). Nas reações catalisadas a 60 e $80{ }^{\circ} \mathrm{C}$ o produto principal foi sempre o de autoeterificação do álcool, isto é, o éter benzílico (Tabela 3). 
Tabela 2. Efeito do tamanho de partícula das resinas sulfônicas na reação de alquilação do tolueno pelo álcool benzílico ${ }^{(a)}$.

\begin{tabular}{|c|c|c|c|c|c|}
\hline \multirow[t]{2}{*}{ Resina } & \multirow{2}{*}{$\begin{array}{c}\text { Tamanho de partícula } \\
(\mathrm{mm})\end{array}$} & \multirow{2}{*}{$\begin{array}{c}\text { Conversão do álcool } \\
(\%)\end{array}$} & \multicolumn{3}{|c|}{ Distribuição de produtos $^{(\mathrm{b})}(\%)$} \\
\hline & & & Alquilado & Éter & Outros $^{(\mathrm{c})}$ \\
\hline \multirow[b]{2}{*}{ Amb 15} & 0,4 & 49,3 & 35,1 & 55,0 & 9,9 \\
\hline & 0,6 & 39,3 & 34,2 & 58,4 & 7,4 \\
\hline \multirow[b]{2}{*}{ Lew SPC 112} & 0,4 & 20,0 & 22,9 & 71,6 & 5,5 \\
\hline & 0,6 & 20,0 & 18,4 & 75,5 & 6,1 \\
\hline \multirow{2}{*}{ MLS 07} & 0,4 & 67,7 & 39,0 & 54,9 & 6,1 \\
\hline & 0,6 & 27,5 & 35,9 & 56,7 & 7,4 \\
\hline
\end{tabular}

(c) Produtos de dialquilação.

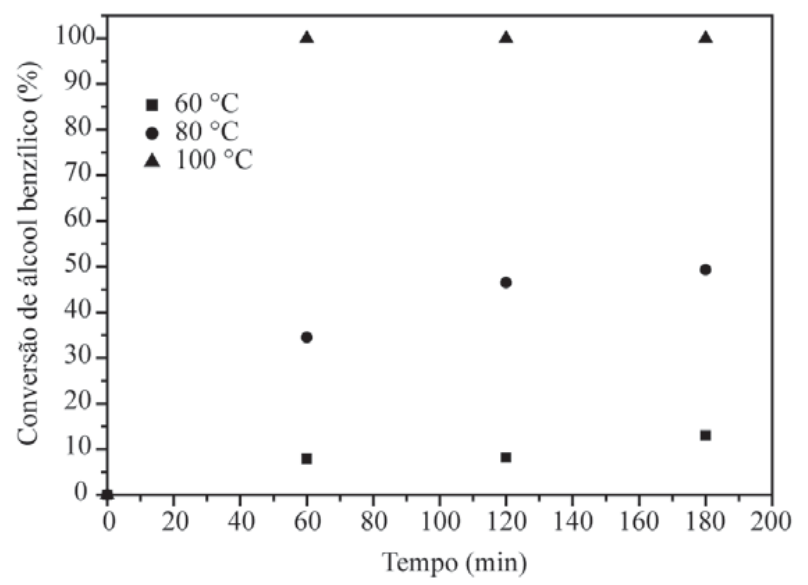

Figura 5. Efeito da temperatura na conversão do álcool nas reações de tolueno com álcool benzílico catalisadas pela resina Amberlyst 15 com tamanho de partícula $0,4 \mathrm{~mm}$.

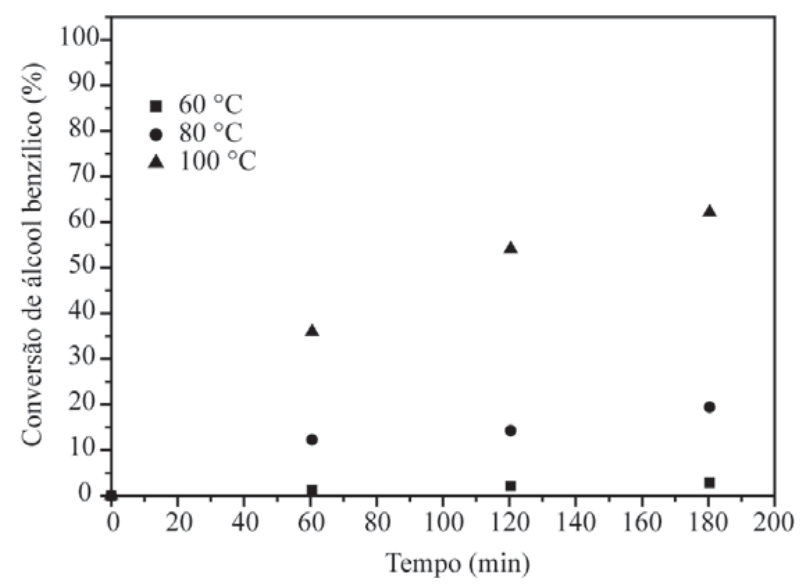

Figura 6. Efeito da temperatura na conversão do álcool nas reações de tolueno com álcool benzílico catalisadas pela resina Lewatit SPC 112 com tamanho de partícula de $0,4 \mathrm{~mm}$.

O aumento da temperatura conduziu a um aumento na conversão do álcool e da proporção do produto de interesse, benziltolueno, indicando que a energia de ativação para a formação desse produto é maior do que para a formação do éter benzílico (reação competitiva), pois houve um favorecimento maior daquela reação com o aumento da temperatura. Além disso, o éter formado pode atuar também como agente de alquilação em temperaturas mais elevadas, o que levaria, mais uma vez, ao aumento da concentração do produto de interesse (benziltolueno).

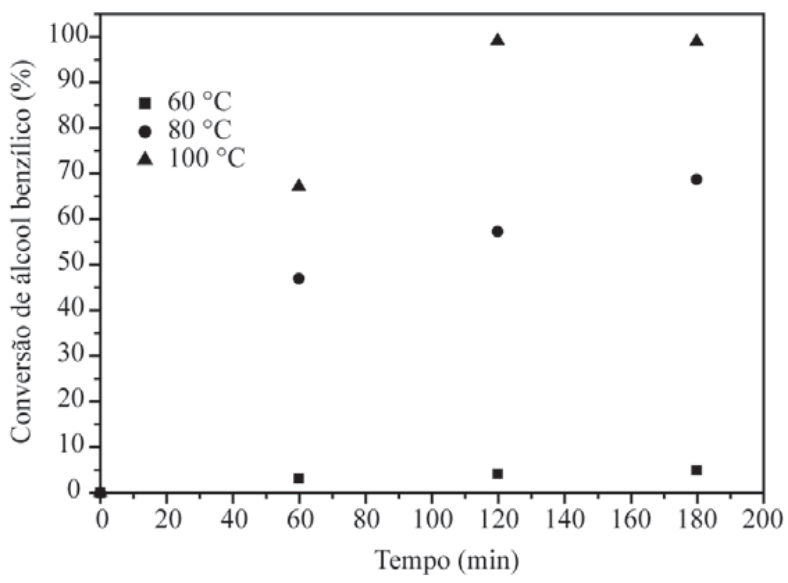

Figura 7. Efeito da temperatura na conversão do álcool nas reações de tolueno com álcool benzílico catalisadas pela resina MLS 07 com tamanho de partícula de $0,4 \mathrm{~mm}$.

Tabela 3. Efeito da temperatura na distribuição dos produtos obtidos na reação do tolueno com álcool benzílico ${ }^{(a)}$

\begin{tabular}{cc|ccc}
\hline Resina & $\begin{array}{c}\text { Temperatura } \\
\left({ }^{\circ} \mathbf{C}\right)\end{array}$ & $\begin{array}{c}\text { Alquilado } \\
\text { Éter (\%) }\end{array}$ & Outros $^{(\mathbf{b})}$ \\
\hline \multirow{4}{*}{ Amb 15 } & 60 & 32,5 & 67,5 & - \\
& 80 & 35,1 & 55,0 & 9,9 \\
& 100 & 76,7 & 15,7 & 7,6 \\
\hline \multirow{4}{*}{ Lew SPC 112 } & 60 & 16,4 & 83,6 & - \\
& 100 & 22,9 & 71,6 & 5,5 \\
MLS 07 & 60 & 38,7 & 61,0 & 0,3 \\
\hline \multirow{4}{*}{} & 80 & 23,5 & 60,1 & 16,4 \\
& 100 & 39,0 & 54,9 & 6,1 \\
\hline
\end{tabular}

(a) $180 \mathrm{~min}$; (b) produtos de dialquilação.

\section{Efeito do tipo de catalisador}

As análises das Figuras 8 e 9 indicam que, os melhores resultados de conversão do álcool foram obtidos com as resinas Amberlyst 15 e a resina MLS 07. Esses resultados se devem provavelmente a menor área específica e capacidade de troca iônica da resina Lewatit SPC 112, em relação às resinas Amberlyst 15 e MLS 07.

A formação do éter benzílico em todas as reações realizadas deve estar intimamente relacionada à acidez do catalisador e, provavelmente, à formação de água durante a reação. Os grupos sulfônicos da resina protonam a água gerando grupos hidroxônio $\left(\mathrm{H}_{3} \mathrm{O}^{+}\right)$que são menos ácidos que os primeiros. Cornélis e colaboradores ${ }^{[14]}$ estudaram a rea- 
ção de tolueno com álcool benzílico catalisada por argila ácida e verificaram que nas condições de reação empregada, isto é, na proporção molar tolueno/álcool/catalisador de 100:5:0,25 g, respectivamente, e temperatura de $80{ }^{\circ} \mathrm{C}$, a conversão do álcool foi de $100 \%$ após $45 \mathrm{~min}$, sendo obtido $30 \%$ do produto alquilado.

Yadav e colaboradores ${ }^{[15]}$ estudaram a reação de tolueno com álcool benzílico e cloreto de benzila catalisada por diferentes sólidos ácidos e verificaram que na reação catalisada por zircônia sulfatada (sólido superácido), a conversão do álcool após 90 min de reação, a $80{ }^{\circ} \mathrm{C}$, foi de $16,7 \%$, sendo obtido $31,1 \%$ de produto alquilado e $68,9 \%$ de éter benzílico. Utilizando como catalisador a argila Filtrol (com acidez de Hammet, $\left.\mathrm{H}_{0}=-6,6\right)$ a conversão foi de $19,3 \%$ e foram obtidos $51,6 \%$ de produto alquilado e $48,4 \%$ de éter benzílico. Na presença da resina Amberlyst $15\left(\mathrm{H}_{0}=-2,2\right)$, a conversão foi de $39,6 \%$, formando-se $44,0 \%$ de produto alquilado e $55,9 \%$ de éter benzílico. Olah e colaboradores ${ }^{[12]}$ verificaram que na reação do tolueno com álcool benzílico catalisada pela resina superácida NAFION-H $\left(\mathrm{H}_{0}=-12\right)$ o rendimento em produto alquilado foi de $70 \%$ e do éter benzílico foi de $5 \%$.

Neste trabalho foi possível sintetizar uma resina com

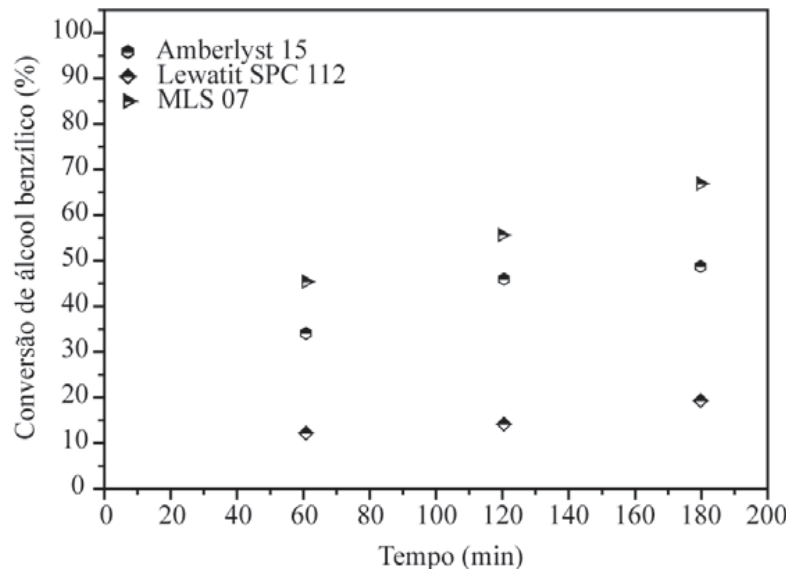

Figura 8. Efeito do tipo de catalisador na conversão do álcool nas reações de tolueno com álcool benzílico catalisadas pelas diferentes resinas com tamanho de partícula de $0,4 \mathrm{~mm}$ a $80^{\circ} \mathrm{C}$.

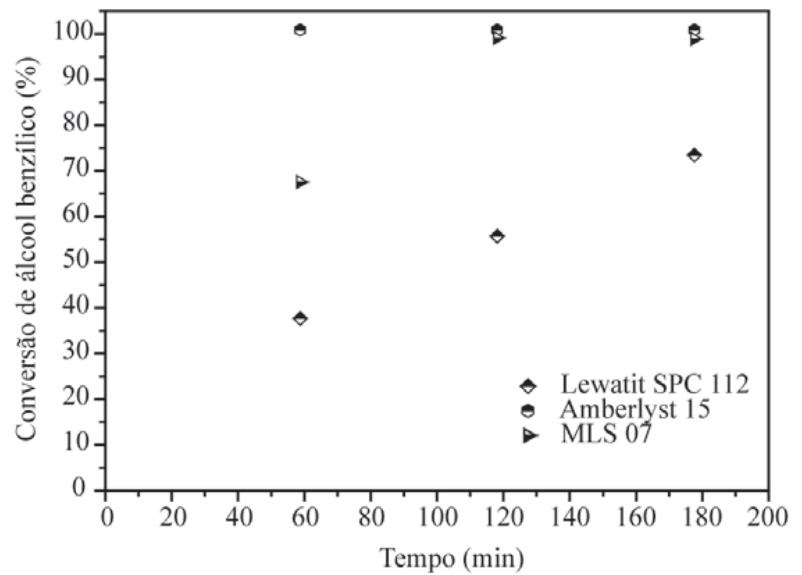

Figura 9. Efeito do tipo de catalisador na conversão do álcool nas reações de tolueno com álcool benzílico catalisadas pelas diferentes resinas com tamanho de partícula de $0,4 \mathrm{~mm}$ a $100{ }^{\circ} \mathrm{C}$. características morfológicas semelhantes à resina comercial Amberlyst-15. Esta resina quando utilizada como catalisador na reação de alquilação de tolueno com álcool benzílico, a $100{ }^{\circ} \mathrm{C}$, apresentou resultados superiores aos encontrados na literatura ${ }^{[15]}$, isto é, a conversão do álcool superior a $90 \%$ e seletividade superior a $70 \%$ no produto de alquilação de interesse. Estes resultados indicam que fatores como morfologia da resina, capacidade de troca e temperatura de reação são parâmetros importantes para a otimização do processo.

Está em andamento em nossos laboratórios a síntese de novas resinas sulfônicas macroporosas, que possam apresentar atividade catalítica superior à das resinas comerciais.

\section{Conclusão}

Os resultados obtidos mostraram que a resina sintetizada em laboratório, MLS 07, apresentou resultados comparáveis aos obtidos com a resina Amberlyst 15, provavelmente devido à semelhança morfológica dessas duas resinas. Verificou-se que, nas reações de tolueno com álcool benzílico, catalisadas pelas resinas Amberlyst 15, Lewatit SPC 112 e MLS 07 a $60{ }^{\circ} \mathrm{C}$, as conversões do álcool foram muito baixas $(<10 \%)$. A resina Lewatit SPC 112 apresentou menor atividade e seletividade no produto de interesse em todas as condições de reação utilizadas neste trabalho. Provavelmente, este resultado deve-se à menor área específica e menor número de grupos sulfônicos acessíveis, deste material em relação à resina comercial Amberlyst 15 e à resina MLS 07. Verificou-se, em todos os casos, que um aumento da temperatura reacional acarreta em um aumento da conversão do álcool, junto com o aumento do produto de alquilação de interesse.

\section{Agradecimentos}

Os autores agradecem ao CNPq, FAPERJ (Bolsa Cientistas de Nosso Estado e Bolsa de Apoio Técnico) e à FINEP pelo auxílio financeiro.

\section{Referências Bibliográficas}

1. Sheldon,R.A. J. Mol. Catal. 107, p. 75, 1996.

2. Tanabe, K.; Holderich, W.F. Applied Catal. A 181, p. 339, 1999.

3. Halgeri, A.B.; Das, J. Appl. Catal. A 181, p. 347, 1999.

4. Chakrabartti, A.; Sharma, M.M. React.\& Functional Polym. 20, p. $1,1993$.

5. Misono, M.; Okuhara, T. Chemtech, 22, 1993.

6. Da, Z.; Magnoux, P.; Guisnet, M. Appl Catal. A 182, p. 407, 1999.

7. Magnoux P.; Mourran, A.; Bernard, S.; Guisnet M. Heterogeneous Catalysis and Fine Chemistry 108, p. 107, 1997.

8. Smith, K.; Polland G.M.; Matthews I. Green Chemistry p. 75, 1999.

9. Sharma, M.M. React.\& Functional Polym., 26, p. 3, 1995.

10. Harmer, M.A.; Sun, Q. Appl Catal. A 221, p. 45, 2001.

11. Olah, G.A.; Prakash, G.K.S.; Sommer, J. Superacids, John Wiley\& Sons, New York, 1985.

12. Yamato,T.; Hideshima, C.; Prakash, G.K.S.; Olah, G. J. Org. Chem. 56, p. 2089, 1991.

13. Silva, M.S.; Costa, C.L.; Pinto, M.M.; Lachter, E.R. Reactive Polymers, 25, p. 55, 1995.

14. Cornélis, A.; Dony, C.; Laszlo, P.; Nsunda, K.M. Tetrah. Lett. 32, p. 2903, 1991.

15. Yadav, G.D.; Thorat, T.S.; Kumbhar, P.S. Tetrah. Lett. 34, p. $529,1993$.

Recebido: $22 / 08 / 2002$

Aprovado: 11/05/2003 